\title{
Dimensioning and Modeling of a Circular Inductor Integrated in a Boost Converter
}

\author{
Y. Benhadda ${ }^{1, *}$, A. Hamid ${ }^{1}$, T. Lebey ${ }^{2}$ \\ 1 University of Sciences and Technology of Oran (USTO-MB) 31000, Algeria \\ ${ }^{2}$ University of Paul Sabatier, Laplace Laboratory, Toulouse, France
}

(Received 18 June 2016; revised manuscript received 22 November 2016; published online 29 November 2016)

\begin{abstract}
This paper presents the dimensioning and modeling of a circular inductor integrated in a Boost micro converter. At first, we define the characteristics of the Boost micro converter, which is the starting point for the design our component, taking into account the electrical and magnetic characteristics of the materials selected. The second, a Boost micro converter schematic simulation coupled with ideal and integrated inductor was presented. This conceptual model of the Boost is best understood in terms of the relation between voltage and current of the inductor. Finely, we have simulated the electromagnetic effects in integrated inductor in the air, and with substrate using the finite element method.
\end{abstract}

Keywords: Circular inductor integrated, Boost converter, Electromagnetic, Finite element method.

\section{INTRODUCTION}

The dimensioning and modeling of the integrated component knows a renewed interest because even the density of components on substrates whose dimensions have experienced a reverse progression [1]. In this regard, several studies were conducted [2], first by the development of a design, modeling and the simulation of a square planar micro-transformer [3], the study and modeling of the micro coil using the finite element method [4] and finally the design and modeling of inductor integrated in a Buck micro converter [5]. The aim of our work is a dimensioning a circular inductor that will be integrated in a Boost micro converter. We have implemented the literature processes for the design of our inductor and calculation of geometry parameters characterizing our component. We have also developed the electromagnetic model using the finite element method.

\section{PRESENTATION OF THE BOOST MICRO- CONVERTER}

We have chosen a Boost micro converter (Fig. 1). The inductor to integrate will thus be dimensioned for this type of application. Input voltage, $V_{i n}=2.5$ Volt . Output voltage, $V_{\text {out }}=5$ Volt . Maximum current $I_{L \max }=2 \mathrm{~A}$. Output power, $P_{\text {out }}=4 \mathrm{~W}$. Frequency of operation, $f=1 \mathrm{MHz}$.

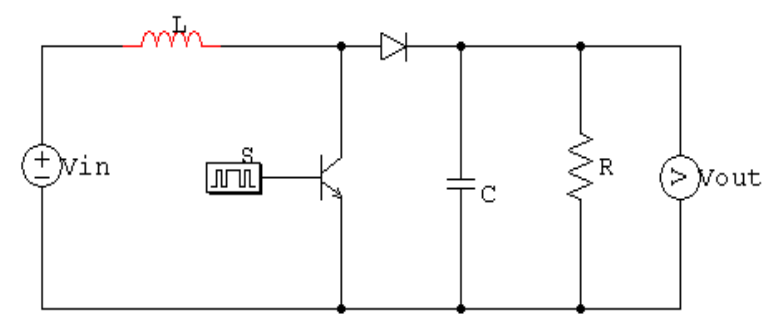

Fig. 1 - Boost converter
The average output current $I_{\text {out }}$ is calculated by formula (1)

$$
I_{\text {out }}=\frac{P_{\text {out }}}{V_{\text {out }}}
$$

The current through the inductor is calculated by formula (2)

$$
I_{L \min }=2 I_{\text {out }}-I_{L \max }
$$

The average current $I_{L}$ is expressed as follows (3)

$$
I_{L}=I_{L \max }+I_{L \text { min }}
$$

We can calculate the value of the inductance $L$ according to relation (4)

$$
L=\frac{\alpha \cdot(1-\alpha) \cdot V_{o u t}}{I_{L} \cdot f}
$$

Where,

$$
\alpha=1-\left(V_{\text {in }} / V_{\text {out }}\right)
$$

The maximum energy stored in the inductor is given by relation (6)

$$
W=\frac{1}{2} L I_{\text {out }}^{2}
$$

The volumetric energy density of the ferrite is given by the equation (7)

$$
W_{v \max }=\frac{B_{\max }^{2}}{2 \mu_{0} \mu r}
$$

$B_{\max }$ : The maximum magnetic induction supported by the ferrite

$\mu_{r}$ : The relative permeability

\footnotetext{
*benhadda_yamina@yahoo.fr
} 
$\mu_{0}$ : The magnetic permeability of the free space

The volume of the ferrite is given by relation (8)

$$
V o l=\frac{W}{W_{v \max }}
$$

The ferrite's thickness is $t_{\mathrm{Sub}}=96 \mu \mathrm{m}$, thus the volume will be $3100 \times 3100 \times 96 \mu \mathrm{m}^{3}$.

\section{DIMENSIONING OF INTEGRATED CIRCU- LAL INDUCTOR}

The geometry parameters characterizing the integrated inductor (Fig. 2) are the number of turns n, the width of the conductor $\mathrm{w}$, thickness of the conductor $\mathrm{t}$, the spacing between conductor s, length of the conductor 1 , the outer diameter dout and input diameter $d_{\text {in }}[6]$.

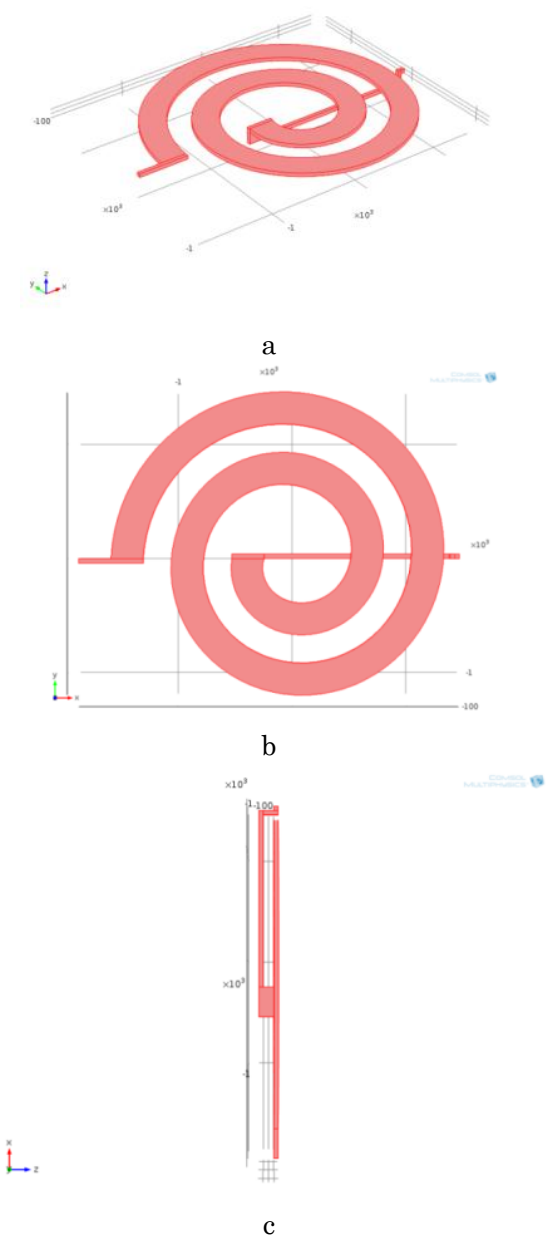

Fig. 2-Geometry of integrated circular spiral inductor, (a) general view, (b) view dessu, (c) front view

We find in the literature several formulas which allow us to calculate the number of turns $\mathrm{n}$ according to the value of inductance $\mathrm{L}$, we chose the Mohan's formula (9). The coefficients $C_{1}, C_{2}, C_{3}$ and $C_{4}$ are defined for each geometry. For a circular inductor spiral, $C_{1}=1, C_{2}=2.46, C_{3}=0$ and $C_{4}=0.2[7]$.

$$
L=\frac{\mu_{0} n^{2} d_{\text {avg }} C_{1}}{2}\left\{\ln \left(\frac{C_{2}}{\rho}\right)+C_{3} \rho+C_{4} \rho^{2}\right\}
$$

Where, we define the average diameter as $d_{\text {avg }}=\left(d_{\text {out }}+d_{\text {in }}\right) / 2$ [8]. $A_{m}$ the factor's form defined as $A_{m}=d_{\text {out }}-d_{\text {in }} / d_{\text {out }}+d_{\text {in }}$.

The spacing between conductors is expressed as follows (10)

$$
s=\frac{d_{\text {out }}+d_{\text {in }}-2 w n}{2(n-1)}
$$

The length of the trace is expressed as follows (11)

$$
l=p i . n \cdot d_{\text {avg }}
$$

The skin thickness is defined as (12)

$$
\delta=\sqrt{\frac{\rho}{\pi \mu f}}
$$

Where $\rho$ represent the resistivity of the conductor, $\rho_{\text {Copper }}=1.7 \cdot 10^{-8} \Omega \cdot \mathrm{m}$ and $\mu$ its magnetic permeability. So that the current flows in the entire conductor, it is necessary that one of the following conditions is filled, $w \leq 2 \delta$ or $t \leq 2 \delta$. Table 1 contains the specifications and the design results of the circular spiral integrated inductor.

Table 1 - Design results of the circular spiral integrated inductor

\begin{tabular}{|l|l|}
\hline Parameter & Value \\
\hline Inductance, $L(\mu \mathrm{H})$ & 0.5 \\
\hline External diameter, $d_{\text {out }}(\mathrm{mm})$ & 3 \\
\hline Internal diameter, $d_{\text {in }}(\mathrm{mm})$ & 0.9 \\
\hline Number of turns, $n$ & 2 \\
\hline Thickness of the conductor, $t(\mu \mathrm{m})$ & 40 \\
\hline Width of the conductor, $w(\mu \mathrm{m})$ & 280 \\
\hline Spacing between conductor, $s(\mu \mathrm{m})$ & 245 \\
\hline Length of the conductor, $l(\mathrm{~mm})$ & 15.9 \\
\hline
\end{tabular}

\section{ELECTRICAL MODEL}

The equivalent electrical model of the integrated inductor [9-10] is shown in Fig. 3.

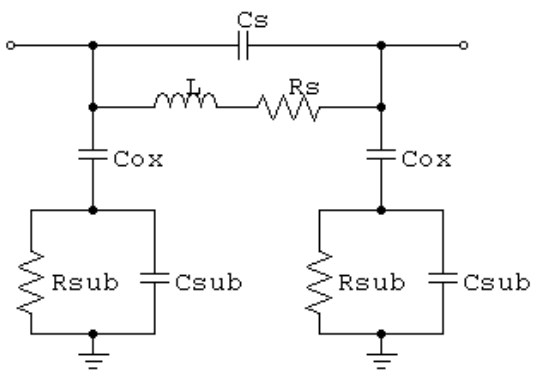

Fig. 3 - Equivalent electrical model

The series resistance $R_{s}$, can be approximated as (13)

$$
R_{s}=\frac{\rho l}{w t}
$$


The parasitic capacitive can be modeled as $C_{s}(14)$

$$
C_{s}=t l \frac{\varepsilon_{0} l}{s}
$$

Where, $\varepsilon_{0}$ is the permittivity of free space, $\varepsilon_{0}=8.854187 .10^{-12} \mathrm{Mm}^{-1}$.

The substrate capacitance $C_{\text {sub }}$ and resistance $R_{\text {sub }}$ are approximately proportional to the area occupied by the integrated inductor and can be expressed as (15), (16).

$$
\begin{aligned}
& C_{s u b}=\frac{1}{2} \varepsilon_{0} \varepsilon_{r} \frac{l w}{t_{s u b}} \\
& R_{s u b}=2 \rho_{s u b} \frac{t_{s u b}}{l w}
\end{aligned}
$$

Cox oxide capacitance $\mathrm{SiO}_{2}$ can be expressed as (17)

$$
C_{o x}=l w\left(\frac{\varepsilon_{0} \varepsilon_{o x}}{t_{o x}}\right)
$$

Where $\varepsilon_{r}, \rho_{\text {sub }}$ represent respectively the relative permittivity and the resistivity of substrate and $t_{o x}$ the oxide thickness. In our case, $\varepsilon_{r}=10$, $\rho_{\text {sub }}=45.10^{-6} \Omega \mathrm{m}$ and $t_{o x}=140 \mu \mathrm{m}$.

The efficiency of integrated inductor is calculated [11-13] according by relation (18)

$$
Q=2 \pi \frac{\text { stocked energie }}{\text { dissipated energie }}
$$

Table 2 presents electrical parameters of the integrated circular spiral inductor.

Table 2-Electricals parameters of the integrated circular spiral inductor

\begin{tabular}{|l|l|}
\hline Electricals parameters & Values \\
\hline$R_{s}(\Omega)$ & 0.0241 \\
\hline$R_{\text {sub }}(\Omega)$ & 0.002 \\
\hline$C_{s}(p F)$ & 0.023 \\
\hline$C_{o x}(p F)$ & 15.37 \\
\hline$C_{\text {sub }}(p F)$ & 2.03 \\
\hline$Q$ & 58 \\
\hline
\end{tabular}

Fig. 4 shows the shape of the quality factor as a function of frequency.

\section{SIMULATION OF THE OF THE BOOST MI- CRO CONVERTER}

In this simulation, the circuit of Fig. 6 contains an ideal inductor and the Fig. 7 shows the waveform of the output voltage and current of the Boost micro converter. The basic principle of a Boost converter consists of two distinct states (Fig. 5, Fig. 6):

- in the On-state, resulting in an increase in the in ductor current;

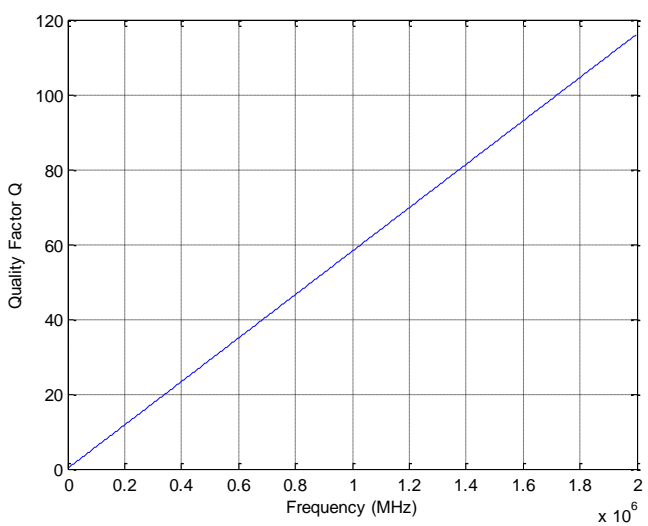

Fig. 4 -Quality factor $Q$ from integrated inductor

- in the Off-state, the only path offered to inductor current is through the diode $D$, the capacitor $C$ and the load $R$. This result in transferring the energy accumulated during the On-state into the capacitor. The current through the inductor $\left(I_{L}\right)$ never falls to zero.

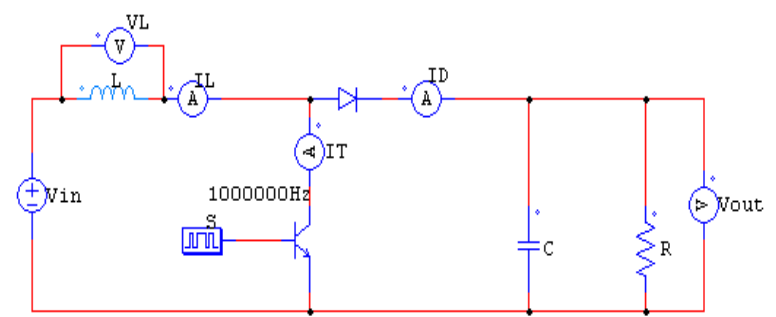

Fig. 5 - Schematic of boost micro converter coupled with ideal inductor

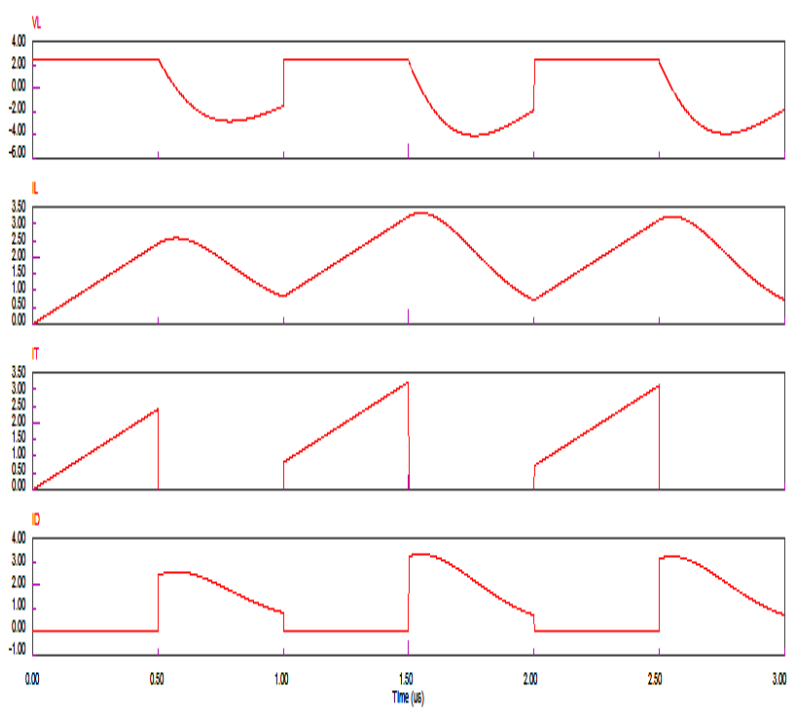

Fig. 6 - Waveforms of voltage and current of boost micro converter coupled with ideal inductor

Fig. 7 shows the schematic of micro converter simulated coupled with integrated inductor. The simulated results are indicated in Fig. 8 . We observe the same result with ideal and reel inductor. 


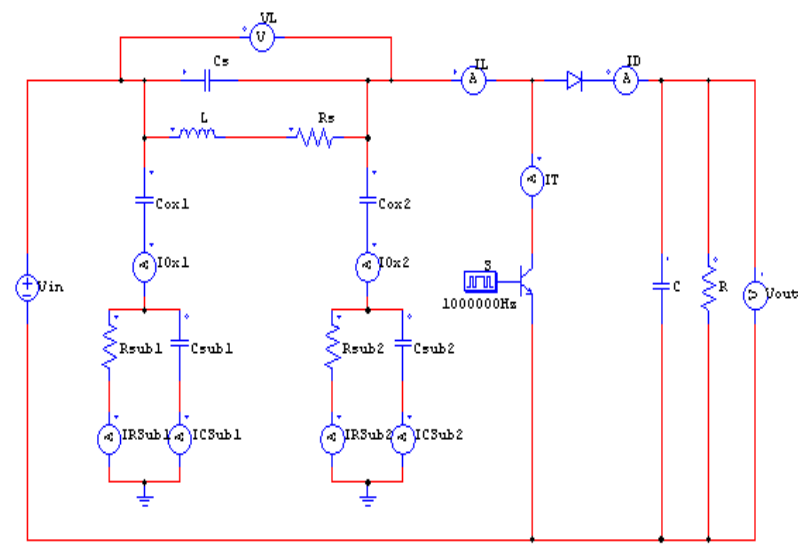

Fig. 7 - Schematic of boost micro converter coupled with integrated inductor
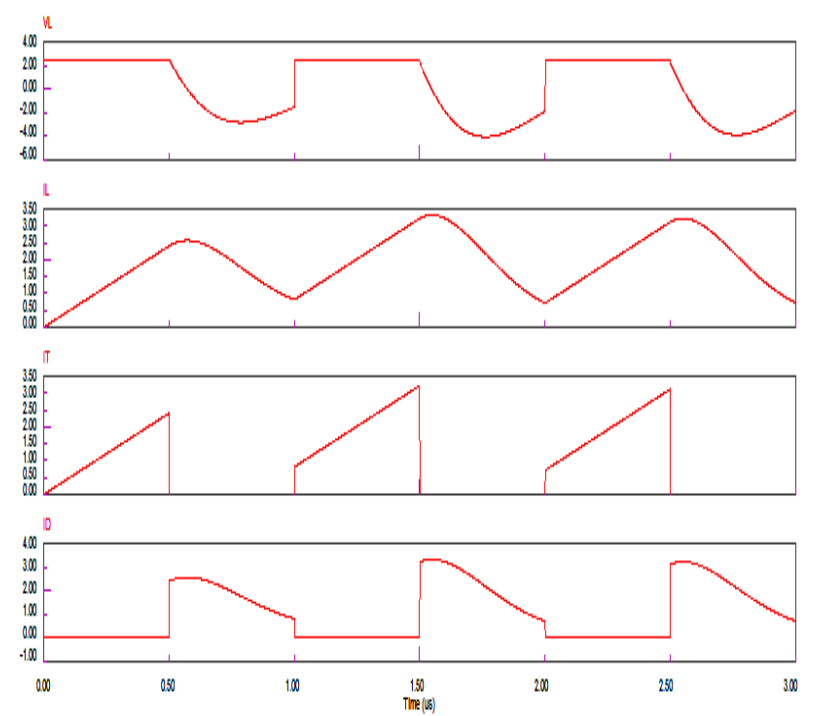

Fig. 8 - Waveforms of voltage and current of boost micro converter coupled with integrated inductor

The results we obtained (Fig. 7, Fig. 9) were compared with those from the literature [14]. We notice the same evolutions therefore quite acceptable and in very good agreement.

\section{ELECTROMAGNETIC EFFECT OF A CIRCU- LAR INDUCTOR}

In this section, we present the distribution of the electromagnetic field in an inductor in the air and on substrate using finite elements method.

The electrics characteristics of materials are shown in Table 3.

Table 3 - Electrics characteristics of the materials

\begin{tabular}{|l|l|l|}
\hline Element & Materiel & Characteristics \\
\hline Conductor & Copper & Electrical conductivity: \\
& $(\mathrm{Cu})$ & $\sigma=5.998107 \mathrm{\Omega}^{-1} \mathrm{~m}^{-2}$ \\
& & Relative permeability: \\
& & $\mu_{x}=1$ \\
& & Relative permittivity: \\
& & $\mathrm{\varepsilon}_{\mathrm{x}}=1$ \\
\hline
\end{tabular}

\begin{tabular}{|c|c|c|}
\hline Substrate & $\begin{array}{l}\text { Ferrite } \\
\text { (NiFe) }\end{array}$ & $\begin{array}{l}\text { Electrical conductivity: } \\
\sigma=2.2104 \Omega^{-1} \mathrm{~m}^{-2} \\
\text { Relative permeability: } \\
\mu_{x}=800 \\
\text { Relative permittivity: } \\
\varepsilon_{x}=10\end{array}$ \\
\hline Oxide & $\begin{array}{l}\text { Silicon di- } \\
\text { oxide } \\
(\mathrm{SiO} 2)\end{array}$ & $\begin{array}{l}\text { Electrical conductivity: } \\
\sigma=1 \Omega^{-2} \mathrm{~m}^{-2} \\
\text { Relative permeability: } \\
\mu_{x}=3.9 \\
\text { Relative permittivity: } \\
\varepsilon_{x}=1\end{array}$ \\
\hline Dielectric & Air & $\begin{array}{l}\text { Electrical conductivity: : } \\
\sigma=1 \Omega^{-2} \mathrm{~m}^{-2} \\
\text { Relative permeability: } \\
\mu_{x}=1 \\
\text { Relative permittivity: } \\
\varepsilon_{x}=1\end{array}$ \\
\hline
\end{tabular}

In Fig. 9, we observe 3D mesh of integrated inductor in the air.

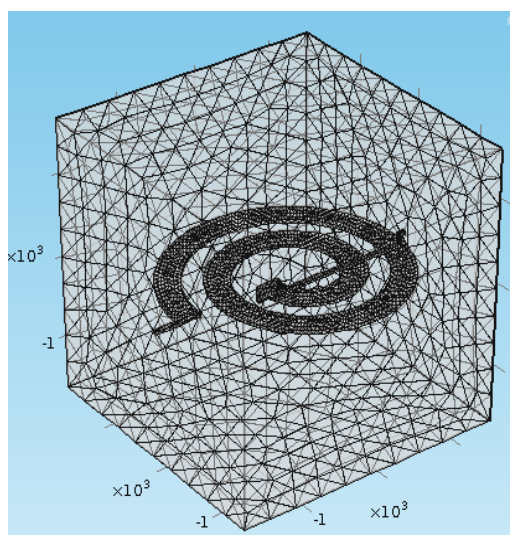

Fig. 9 - 3D mesh of inductor in the air

Fig. 10 shows the distribution of the electric field and magnetic field lines in the inductor in the air.

This electric field is important to the input of the component. The magnetic flux density lines are concentrated around the component and are bounded by the borders. The results we obtained (Fig. 10) were compared with those from the literature [15]. We notice the same distributions therefore quite acceptable and in very good agreement.

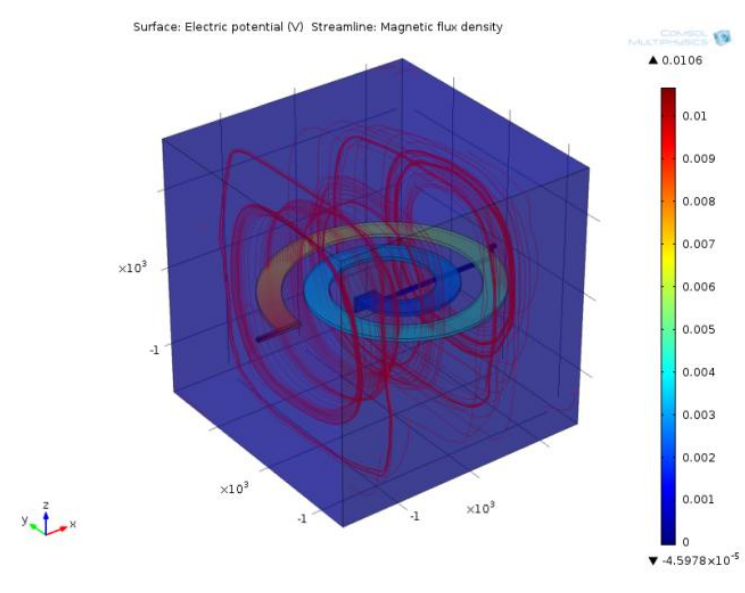




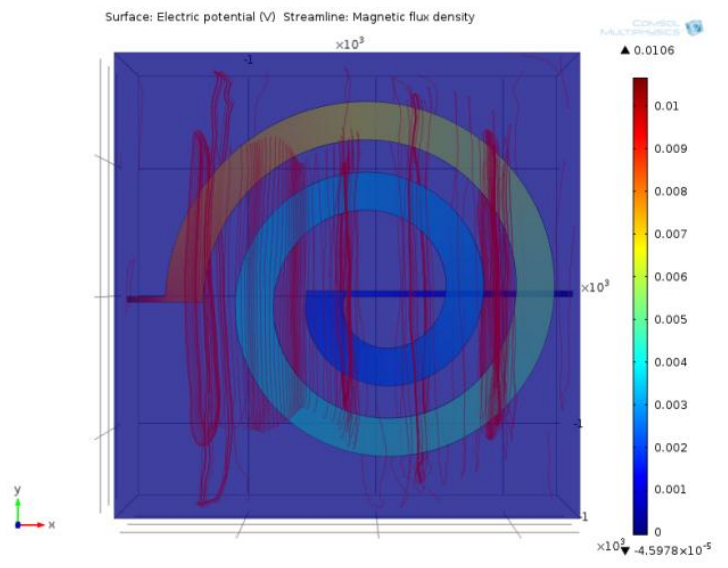

$\mathrm{b}$

Fig. 10 - Distribution of magnetic field lines in the inductor in the air, (a) general view

In Fig. 11, we observe 3D mesh of integrated inductor on substrate.

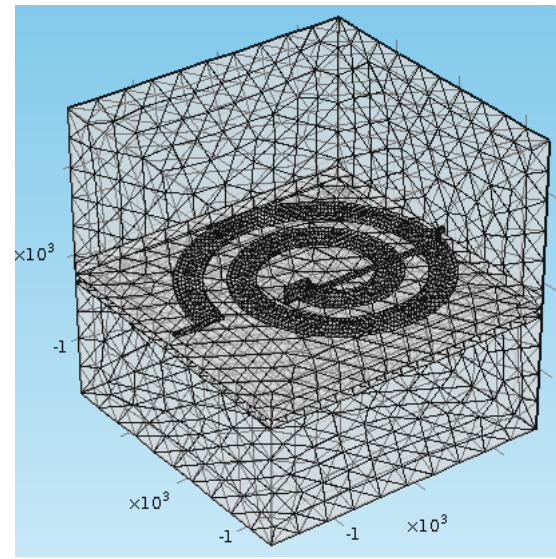

Fig. 11 - 3D mesh of inductor on substrate

Fig. 12 shows the distribution of the electric field and the magnetic field lines in the inductor on substrate. Still, the electric field is maximum at the input of the integrated inductor. The magnetic field lines are concentrated in the magnetic core, the ferrite (NiFe) which limits the disruption of our component. The results we obtained (Fig. 12) were compared with those from the literature [16]. We notice the same distributions therefore quite acceptable and in very good agreement.

\section{REFERENCES}

1. C. Liu, H. Chang, K. Li, C. Lin, C. Hsu, T. Lin, H. Chou, H. Huang, H. Liao, IEEE Electron. Component. Technol. Conference 1675 (2013).

2. M.H. Belghazi, Université de Limoges (2008).

3. M. Derkaoui, A. Hamid, T. Lebey, R. Melati, Telkomnika 11 No 4, 669 (2013).

4. A. Allaoui, A. Hamid, P. Spiterri, V. Bley, T. Lebey, J. Low Power Electron. 11 No 1, 63 (2015)

5. Y. Benhadda, A. Hamid, T. Lebey, M. Derkaoui, J. NanoElectron. Phys. 7 No 2, 02006 (2015).

6. P. Gomes, Université de Lisboa (2011).

7. H. Xu, Université de California (2005).

8. C. Somo, D. Malec, V. Bley, IEEE T. Adv. Packaging 1 (2008).
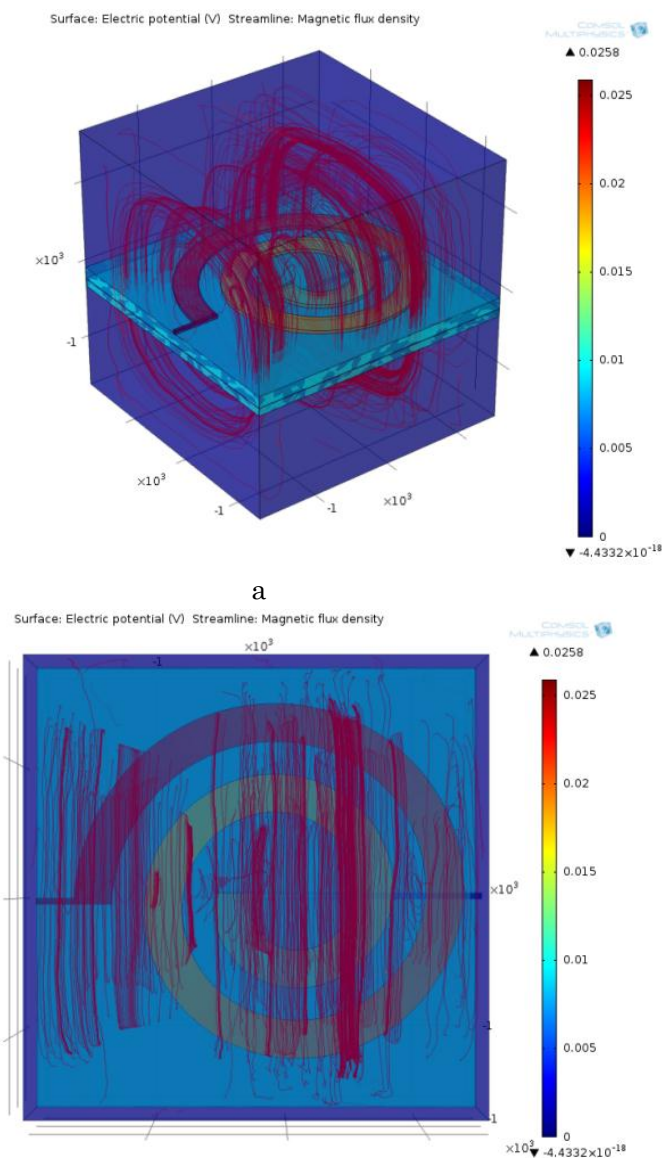

Fig. 12 - Distribution of magnetic field lines in the inductor on substrate, (a) general view, (b) view dessu

\section{CONCLUSION}

In this paper we addressed the dimensioning and modeling of a circular inductor integrated in a boost converter. We have implemented the literature methods for the design and dimensioning of our integrated inductor, based on the finite element method. We have visualized the electromagnetic phenomenon in inductor in the air and on substrate. We conclude that when we insert a substrate, the majority of the magnetic field lines are concentrated at the walls of the magnetic block. So, the substrate layer is required to have a good electromagnetic compatibility in the case of the integration inductor.

9. N.Kr. Shukla, S. Birla, R.K. Singh, Int. J. Eng. Technol. 2 No 1,48 (2010).

10. A. Eroglu, 35, 53 (2011).

11. I. Bahl, University of Boston-London (2003).

12. C.H. Liu, H.D. Chang, K.H. Li, C.H. Lin, C.J. Hsu, T.Y. Lin, H.H. Chou, H.C. Huang, H.Y. Liao, IEEE 1675 (2013).

13. J. Wei, Z. Wang, IEEE Electron Dev. Lett. 31 No 9, 933 (2010).

14. P. Sharma, M. Mehta, Int. J. Sci. Eng. Res. 3 No 2 , 1 (2012).

15. S. Couderc, Université de Limoges (2006).

16. Y. Benhadda, A. Hamid, T. Lebey, A. Allaoui, M. Derkaoui, R. Melati, Telkomnika, 14 No 2, 669 (2015). 